\title{
Human Intelligence Development: Challenges and Way Forward
}

Siti Noor Mawar A. Rahman \& Azrin Ibrahim

To Link this Article: http://dx.doi.org/10.6007/IJARBSS/v11-i11/11547

DOI:10.6007/IJARBSS/v11-i11/11547

Received: 17 September 2021, Revised: 20 October 2021, Accepted: 30 October 2021

Published Online: 07 November 2021

In-Text Citation: (Rahman \& Ibrahim, 2021)

To Cite this Article: Rahman, S. N. M. A., \& Ibrahim, A. (2021). Human Intelligence Development: Challenges and Way Forward. International Journal of Academic Research in Business and Social Sciences, 11(11), 475 $-483$.

\section{Copyright: (c) 2021 The Author(s)}

Published by Human Resource Management Academic Research Society (www.hrmars.com)

This article is published under the Creative Commons Attribution (CC BY 4.0) license. Anyone may reproduce, distribute, translate and create derivative works of this article (for both commercial and non-commercial purposes), subject to full attribution to the original publication and authors. The full terms of this license may be seen at: http://creativecommons.org/licences/by/4.0/legalcode

\section{Vol. 11, No. 11, 2021, Pg. $475-483$}

Full Terms \& Conditions of access and use can be found at http://hrmars.com/index.php/pages/detail/publication-ethics 


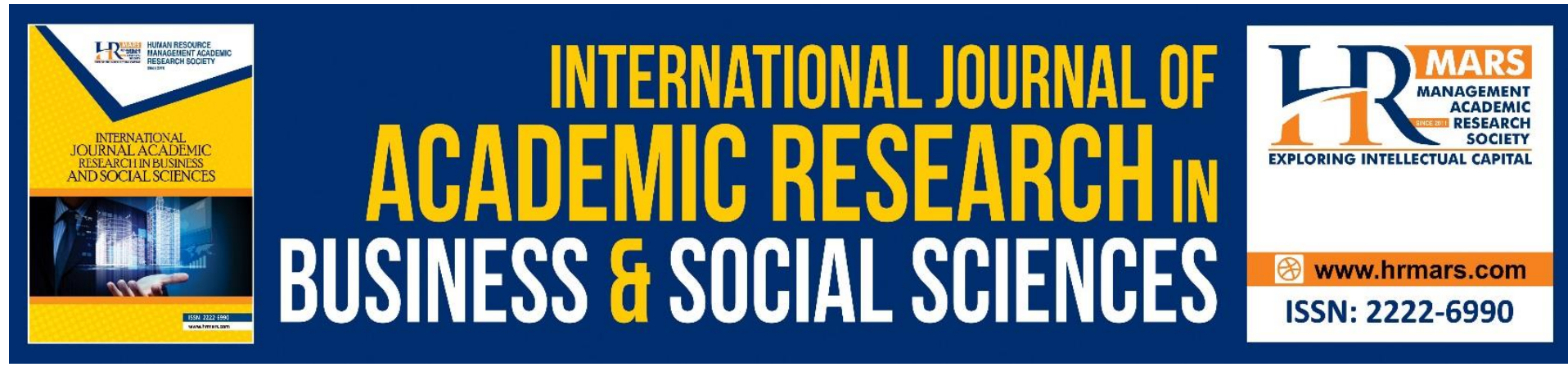

\title{
Human Intelligence Development: Challenges and Way Forward
}

\author{
Siti Noor Mawar A. Rahman \& Azrin Ibrahim \\ Centre for Islamic Development Management Studies (ISDEV) Universiti Sains Malaysia, \\ 11800 Pulau Pinang, Malaysia. \\ Email: snmawarahman@gmail.com
}

\begin{abstract}
What is the challenges in human intelligence development? Inadequate comprehensive theories or the advanced in artificial intelligence? Both have been identified as new challenge in human intelligence development. This paper aims to highlight the challenges in human intelligence development and suggest the way forward. To achieve this goal, existing theories in human intelligence reviewed and the advancement of artificial intelligence studied based on secondary data derived from article journals. The data being analyzed using content analysis. The outcome presented as explanatory to the data gathered at the beginning of this paper and interpretative in nature in the context of human intelligence development result and discussion. The future research in human intelligence development is the way forward being suggested in this paper.
\end{abstract}

Keywords: Comprehensive Human Intelligence, Artificial Intelligence Advancement and Human Intelligence Development

\section{Introduction}

Human intelligence or intelligence has been generated as unitary or multiple dimensions and, in some theory, as narrow or broad abilities. Nonetheless, intelligence instead being viewed as product rather than process have long call for greater attention by theoreticians and clinicians ever since the concepts and theories of intelligence had been established (Lohman, 1989). In recent study, there is still a tendency to view intelligence as product even the issues of intelligence as a process have been long highlighted. As a result, new terms and construct being introduced. Among the new suggestion intelligence as product is ethical intelligence, moral intelligence, mystical intelligence and adaptive intelligence (Quadri, 2021; Sternberg, 2019). However, 'adaptive intelligence' as the word implies argued by Sternberg (2021) to be process rather than another term of product in human intelligence's study. In fact, many issues have been brought to attention for researcher in human intelligence in search for comprehensive understanding of human intelligence. These unresolved issues are also the reason being the development of human intelligence still fall behind if compared to the progress of its rival, artificial intelligence. Therefore, the advancement in the artificial intelligence development also being observed to be ubiquitous issues in human intelligence 
development. To study these issues systematically, the next section discusses about the research method on the issues observed.

\section{Research Method}

Cambridge Advanced Learner's Dictionary (2003) in defining research as 'a detailed study of a subject, especially to discover (new) information or reach a (new) understanding'. In reference to that definition, this research uses basic qualitative research methodology with content analysis. This method allows more quality information obtained without requires large data sample (Hamzah, 2010). By employing qualitative modes of enquiry, data sample from article journal which discuss about 'comprehensive human intelligence' and 'artificial intelligence advancement' being analyzed using content analysis to produce result of new information in understanding "human intelligence development". Therefore, this study was explanatory and interpretative in nature and contains three important key words 'comprehensive human intelligence, artificial intelligence advancement and human intelligence development. The next two section are explanatory in nature and explains data derived from two key words 'comprehensive human intelligence' and "artificial intelligence advancement".

\section{Comprehensive Human Intelligence}

Lohman (1989) in his study of the advanced theory and research of human intelligence has well presented the issues, arguments, controversies, and suggestions in understanding human intelligence. His study provides groundwork in search for comprehensive human intelligence. According to him, ability construct, factor analysis and test are the issues revolve around intelligence where individual differences is a major concern. From factor analysis, many advanced terms emerged as ability construct such as verbal crystallized abilities, fluid reasoning abilities. spatial visualization ability, mental speed. The terms indicate some major shift in the discussion of human intelligence from product to process. Prior to this, popular terms such as emotional intelligence, multiple intelligence and later spiritual intelligence dominated the discussion of human intelligence. At this point of time, some sort of organisation known as quasi hierarchical model ${ }^{1}$ and hierarchical model ${ }^{2}$ has been introduced. Around 1980s, the direction of intelligence discussion made it turning point. When cognitive science took over the discussion of the intelligence phenomena, it adds another term known as general intelligence or ' $g$ ' factor. Instead of single or multiple abilities, process theories which later developed into hierarchical model combining broad and narrow abilities started gaining influence and clearly emphasized the role of general ability. The most

1 The quasi-hierarchical model has two deep processing factors (Fluid Ability and Crystallised Ability, three perceptual organization factors (visualisation, clerical, speed, and auditory thinking), three associational processing factors (short term acquisition and retrieval, long term storage and retrieval, correct decision speed) and two sensory reception factors (visual sensory detection and auditory sensory detection) (Lohman, 1989).

2 the hierarchical model has three levels. The three-level hierarchy includes a General Reasoning factor, G, at the top. Three broad group factors-Crystallized Abilities, FluidAnalytic Abilities, and Short- Term Memory-constitute the second level. Three more specific factors make up the third level (Lohman, 1989). 
popular theories combining broad and narrow abilities are Structure of Intellect (SOI) ${ }^{3}$ proposed by Guilford (1985) and Triarchic theory of intelligence ${ }^{4}$ by Sternberg (1985). Sternberg (2019) in his further investigation, link the ' $g$ ' factor with his theory of 'adaptive intelligence'. According to him intelligence typically consisting of 'adaptation to the environment' and there is some similarities and differences with general intelligence.

The search for comprehensive human intelligence also can be found in another area of psychological research. In an investigation into psychological dilemma of moral reasoning abilities, Hamzah, Yusoff \& Razak (2011) have presented the comprehensive integration of cognition, emotion and spiritual and managed to identify process, dimension and products in their studies of philosophical underpinning of schemata development. They also produced test and measurement of moral reasoning abilities which blend intelligent quotient (IQ), emotional quotient (EQ) and spiritual quotient (SQ). Their work contributes greatly to some understanding of comprehensive human intelligence through Islamic perspective even it lacks in term of structure of hierarchical process. However, the structure of schemata development shows process, major and minor components as well outcome (product) that could be recognised as part of comprehensive human intelligence.

Most significant area that contributes to intelligence is cognitive psychology. Cognitive psychology is an area in psychology which study the internal mental process that deals with perception, thinking, memory, attention, language, problem solving and learning. Its ubiquitous influence on human intelligence's study path the new way to think about what intelligence and other ability tests were really measuring. In fact, it has become the goal in cognitive psychology to understand human intelligence and how it works. Besides that, its influence also paves the way to development of artificial intelligence by stimulating theories of human cognition in computer programmes. The reciprocal relationship of both field computer programming and cognitive psychology contribute significantly to the understanding of the nature of human intelligence and its complexity (Lohman, 1989; Antonov, 2011; Kamar, 2016).

Previous research findings have been consistent and supportive to recognize human intelligence as process first before recognizing it as product. By clearly recognizing it as process, any test measurement developed will measure what it supposes to measure instead measuring limited dimension of human intelligence as product. It not only solves the issues of test and measurement in human intelligence but more importantly it could contribute to the development in human intelligence if comprehensive human intelligence captured clearly. Unfortunately, the research to date has not been able to account of all aspects of human intelligence comprehensively. The lack of certainty in comprehensive human intelligence become major challenge towards its development. Another source of uncertainty is associated with the advancement in artificial intelligence (Al).

\footnotetext{
3 It is a theory of three- way classification: by the kind of mental process required, by the kind of information processed, and by the mental products generated. The combination of five types of mental processes, four types of content, and six types of products defined the 120 abilities in the structure of the intellect model (Lohman, 1989).

${ }^{4}$ Triarchic theory of intelligence contains three sub theories: a contextual sub theory, an experiential sub theory, and a componential sub theory (Lohman, 1989).
} 


\section{Artificial Intelligence Advancement}

Al started as the computer as brain imitates much more primitive human rational thinking, low level factor and according to Antonov (2011), human poses unconscious super intelligence not fully explored. Antonov (2011) also added the understanding of the degree of advancement of human intelligence is still incomplete. This statement supports the discussion in previous section. This is the first study, to use the term super intelligence as the ability to analyse and solve unclearly defined multi-factor problems which is remains unsolved in Al.

From computer as brain, advance computer programme has developed from serial processing to parallel processing and interest in advance computer programme has made major shift into displaying Al. In fact, cognitive science provides groundwork for the interaction between computer science, cognitive psychology, linguistic, neuropsychology, philosophy, and instructional psychology. Under the umbrella of cognitive science, the new discovery from those field are predicted to further the advancement in computer programming displaying $\mathrm{Al}$ (Lohman, 1989).

Thus far, the advancement in Al seems to dominate some process in human activities and abilities. Table 1 projected the ratio of Human-Machine working hours for period 2018-2022. The projection shows the increasing number of the machine abilities over human abilities or in other word, computer displaying Al over human intelligence.

Table 1. Ratio of Human - Machine working hours, 2018 vs 2022 (projected)

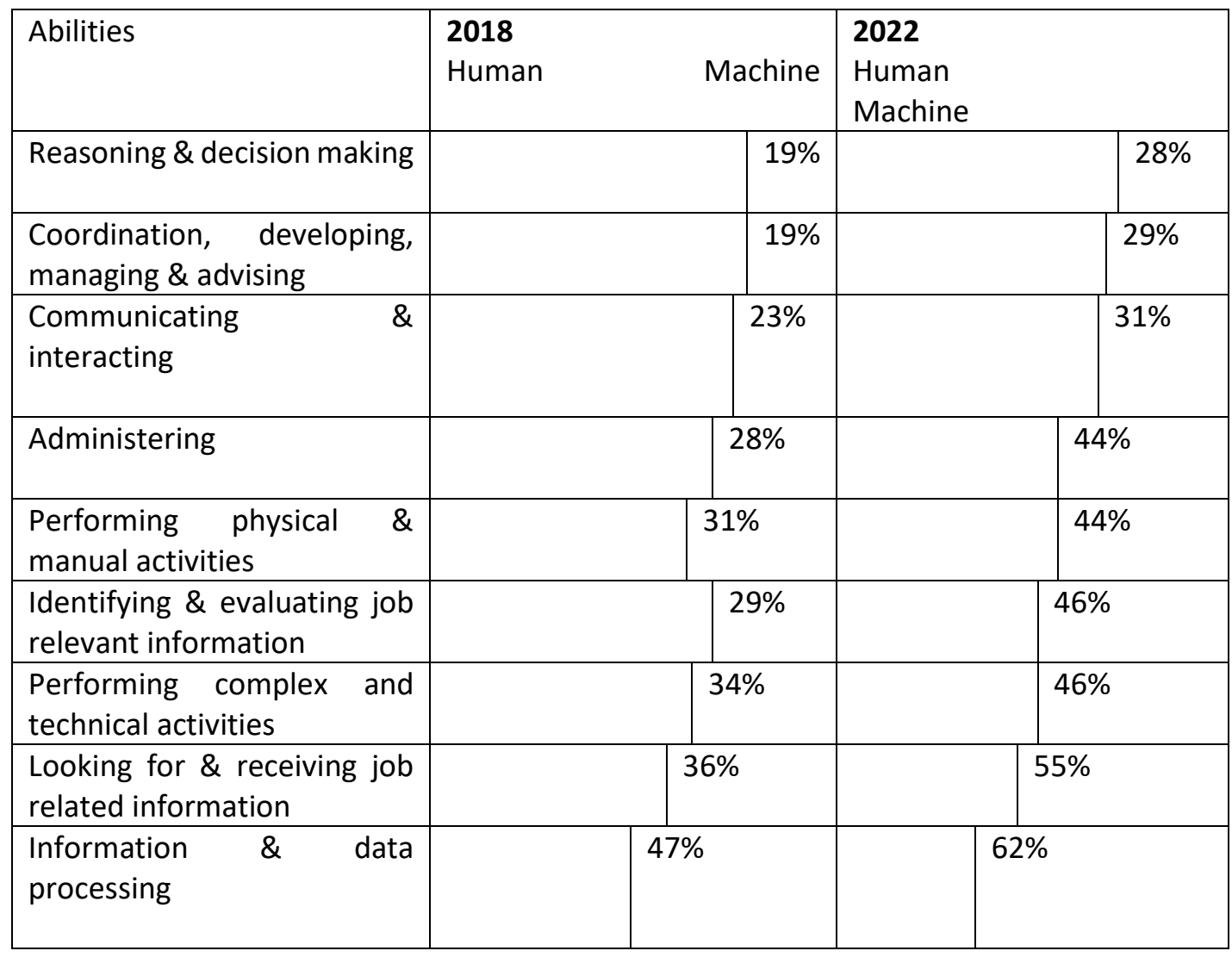

Notes: Taken from Future of Jobs Survey 2018, World Economic Forum 
Above is the reflection on the abilities of computer as machine in dispalying Al over human abilities in some specific area of human intelligence. The abilities identified have been made comparison base on working hours between computer displaying $\mathrm{Al}$ as machine and human from 2018 to 2022 period of projection. If in 2018, the machine working hours is only $19 \%$ in reasoning, decision making, coordination, developing, managing and advising, the working hours of machine will increase to $28-29 \%$ in 2022 . The rest abilities also show the increasing working hours of the machine which looking for and receiving job related infromation as well infromation and data processing show more than half percentage of working hours by the machine.

Even it seems a big challenge to human, Miller (1981) once argued that computational theories completely no account for human cognition since human brain is itself a computer. Therefore, computer that models an intelligent brain is expected to be a brain (Miller, 1981). Most likely Miller argument had been underestimating the abilities of computer displaying $\mathrm{Al}$ abilities. Furthermore, the advancement of Al nowadays might be able to include intuition, intention, desire and belief in its computational logic structure as research in abdicative logic programming (ALP) and belief-desire-intention (BDI) model in progress (Srivastav, 2019) and these far exceed the computer-brain analogy.

Up to this point, the present study has shed a contemporary light on the contentious issues in cognitive psychology and in computer science and summarizes much of what is known about the organization of human abilities. The following is a brief report on a synthesis and evaluation of comprehensive human intelligence and $\mathrm{Al}$ advancement.

\section{Result}

In fact, a model of ability organisation within developmental and information processing has been proposed since 1985. The model combines the hierarchical model of intelligence and the quasi-hierarchical model of intelligence. This model provides foundation to the development of comprehensive human intelligence. It also completes some puzzle in human intelligence development.

Further research in these two hierarchical models seems to provide a more comprehensive scheme considering the ' $\mathrm{g}$ ' factor as in Structure of intellect (SOI) and Triarchic theory. However, critics have been made in their inadequacy of certain elements such as SOI has been criticized of not including auditory elements and Triarchic theory is only concept idea that difficult to make assessment in practical. Recent finding on the element of practise seems to be missing in both theories. This element has been made importance in human intelligence development. The finding of joint influence between intelligence and practise in expertise development showed the moveable benefit more from the same amount of learning style. From this finding, it is noticeable that human intelligence is ill defined by limiting general reasoning abilities as hallmark of intelligence (Vaci et al., 2019).

Process theories of abilities is important to be highlighted here because human intelligence development is not just about the identification of construct but more importantly the identification of the process involved. The best illustration of the process theories abilities comes from the simulation of computer programming displaying $\mathrm{Al}$ as being discussed in previous discussion and also from psychological dilemma in moral reasoning abilities 
(Antonov, 2011; Hamzah et al., 2011). However, the former best referring to the process taking place in brain and the later lack in hierarchical structure as being discovered in previous research in human intelligence. A reasonable approach to tackle this issue could be a focused research in human intelligence development.

This section has explained the incoming challenge in human intelligence development from comprehensive human intelligence and artificial intelligence advancement's perspective. The next section will interpret the finding as a way forward in human intelligence development.

\section{Human Intelligence Development: A Way Forward}

Overall, this study outlines a critical role for searching a comprehensive framework of human intelligence, the need for collaborating human intelligence and $\mathrm{Al}$ as well the need for reviewing educational objective and strategies.

The data reported here appear to support the assumption that attempt in defining the universe of intelligent behaviours, cognitive function or tasks has become central issues in human intelligence. This proves the inadequacy of the comprehensiveness of the study of human intelligence, and it has been proven that the existing intelligence test only pay attention to certain selected task only. Lohman (1989) has clarified this by stating comprehensive framework must establish first before administering intelligence test. "The comprehensive framework of human intelligence can then be used to construct test of different facets of intelligence" (Lohman, 1989). Further studies should attempt to identify this 'comprehensive framework of human intelligence and as a way forward in developing human intelligence.

Comprehensive framework here then can be established by recognising other than cognition aspect. Kants and Wechsler were the scholars considering the affective dimension. Besides affective, Kant also emphasized the importance of intention. Surprisingly, in reviewing the literature, no comprehensive concepts, or theories of human intelligence able to integrate it in a structure of hierarchical process. More research is required in treating comprehensive framework of human intelligence consisting cognitive, affective, intention as well outcome in a structure of hierarchical process. The underpinning factors is the existence of boundaries to treat intelligence, learning and development as three distinct field in psychology. However, these boundaries can be diminished, and more integrated approach can be achieved. In fact, advancement in Al showed how the other dimensions of human intelligence can be integrated in some sort of process (Srivastav, 2019).

Al and its growing abilities to mimic human intelligence should not be viewed as opponent to human intelligence. In some instance, Al helps improve human intelligence development (Lohman, 1989); Srivastav, 2019). Indeed, it gave way to a growing respect for human intelligence and its operation. The finding of this study suggest that human intelligence development and $\mathrm{Al}$ development are at similar importance and promising area of collaboration (Blog, 2020; Srivastav, 2019; Kamar, 2016). The attitude towards Al can also be confirmed to facilitate rather than alternate human intelligence or in other words it is to support super intelligent multi factor system. Kamar (2016) even suggested the term hybrid intelligence to manifest this new phenomenon. Those who would be able to master this system would be able to achieve the best in their life. 
The advancement of $\mathrm{Al}$ also according to (Antonov, 2011), give some insight to what to developed in human. According to him, objective of education must be the development of human intellectual resources, and this provide another important discovery in human intelligence development. However, it has been reported, these human intellectual resources seem to be not clearly defined and identified comprehensively. Antonov (2011) further argued, for intellectual development of people, the system of comprehensive education must be rebuilt and aimed first. Comprehensive education with objective to develop human intellectual resources means might means here to integrate cognition, emotion and spiritual components to form human thinking in shaping individuals moral reasoning. (Hamzah et al., 2011). The product of this kind of education could be in the form of moral intelligence, ethical intelligence, and mystical intelligence (Quadri, 2021).

Initial observations suggest that there may be a link between human intelligence development and Muslim moral structure and belief system as proposed by Hamzah et al., (2011) in their research on moral structure and moral development. The 'philosophical underpinning of schemata development' which serves as working framework of their research could be considered groundbreaking for further research in human intelligence development in Islam. The philosophical framework either need further reviewed or reorganized in the context of human intelligence development.

This section has interpreted and discussed the finding which emerged from the content analysis presented in the previous section. Three major themes emerge from the studies discussed so far, hence provide important insight into the human intelligence development and its way forward.

\section{Conclusion}

The search for comprehensive understanding of the nature, construct, major components, and hierarchical structure is vital for human intelligence development way forward. With recent Al development in computer science, the development for comprehensive organization of human abilities will be a growing interest and respect. The impact of both certainly has direct influence in education system. The education system must identify the need for comprehensive human intelligence development which integrate Al development into its system to prepare its future generation. The finding from this study contribute to the current literature in the context of human intelligence, especially on its development.

\section{Acknowledgement}

Thank you to the Universiti Sains Malaysia (USM) for research funding through Research University Individual (RUI) (1001/CISDEV/8016039) - Grant Title: Psycho-Hisbah Model for Performance Appraisal.

\section{References}

Antonov, A. A. (2011). Realisation of Human Super-Intelligence (Developmental Learning). 8(4), 109-119. Retrieved from http://www.wseas.us/e-library/transaction/education/ 2011/55-269.pdf.

Quadri, A. S. M. A. (2021). The comprehensiveness of Spiritual Intelligence, CIFIA Global Journal, 3.

Blog, D. S. (2020). How ( un- ) intelligent is our collaboration with Al? 1-6. 
Hamzah, A., Yusoff, M. Z. M., \& Razak, N. A. (2011). Investigating IQ, EQ and SQ Components of Malay Muslim Moral Structure in the Course of Psychological Dilemma. International Journal for Cross-Disciplinary Subjects in Education, 2(3), 487-492. https://doi.org/10.20533/ijcdse.2042.6364.2011.0067.

Kamar, E. (2016). Directions in hybrid intelligence: Complementing Al systems with human intelligence. IJCAI International Joint Conference on Artificial Intelligence, 2016-Janua, 4070-4073.

Hassan, S. A., \& Khairuldin, W. M. K. F. W. (2020). Research Design Based on Fatwa Making Process: An Exploratory Study. International Journal of Higher Education, 9(6), 241-246.

Said, N. A., \& Khairuldin. (2017). Freedom of Speech in Islam and its Connection with Street Demonstrations. International Journal of Academic Research in Business and Social Sciences, 7(4), 122-129.

Khairuldin, Embong, A. H., Anas, W. N. I. W. N., Ismail, D., Ibrahim, I., \& Fauzi, N. (2017). Freedom of Speech: A Comparative Study between Islam and Malaysian Laws. International Journal of Academic Research in Business and Social Sciences, 7(2), 22226990.

Ibrahim, I., \& Khairuldin. (2017). Fatwa as a Medium Da'wah: Studies on the Role of Mufti as a Preacher. International Journal of Academic Research in Business and Social Sciences, 7(4), 10-18.

Lohman, D. F. (1989). Human Intelligence: An Introduction to Advances in Theory and Research. Review of Educational Research, 59(4), 333-373. https://doi.org/10.3102/00346543059004333.

Srivastav, A. (2019). Human Thinking with Artificial Intelligence, 4(3), 1-16.

Sternberg, R. J. (2019). A theory of adaptive intelligence and its relation to general intelligence. Journal of Intelligence, 7(4), 1-17. https://doi.org/10.3390/jintelligence7040023.

Vaci, N., Edelsbrunner, P., Stern, E., Neubauer, A., Bilalić, M., \& Grabner, R. H. (2019). The joint influence of intelligence and practice on skill development throughout the life span. Proceedings of the National Academy of Sciences of the United States of America, 116(37), 18363-18369. https://doi.org/10.1073/pnas.1819086116. 